\title{
Geographic Tongue
}

\section{Coğrafik Dil}

\begin{abstract}
Murat Ozturk ${ }^{1}$, Isa An²
${ }^{1}$ Dept. of Dermatology, Health Sciences University, Van Training and Research Hospital, Van, Turkey, ${ }^{2}$ Dept. of Dermatology, Sanliurfa Training and Research Hospital, Sanliurfa, Turkey
\end{abstract}

Dear editor,

A 28-year-old female patient was admitted to the outpatient clinic with the complaint of asymptomatic whiteness on the tongue that had been discontinued for three years. Her medical history was normal. It was learned that her uncle had psoriasis. Dermatological examination revealed white annular-serpiginous hyperkeratotic plaques in the dorsum of the tongue (Fig. 1). There were no cutaneous findings of any skin diseases. The patient refused the biopsy. With clinical features, patient was diagnosed as geographic tongue.

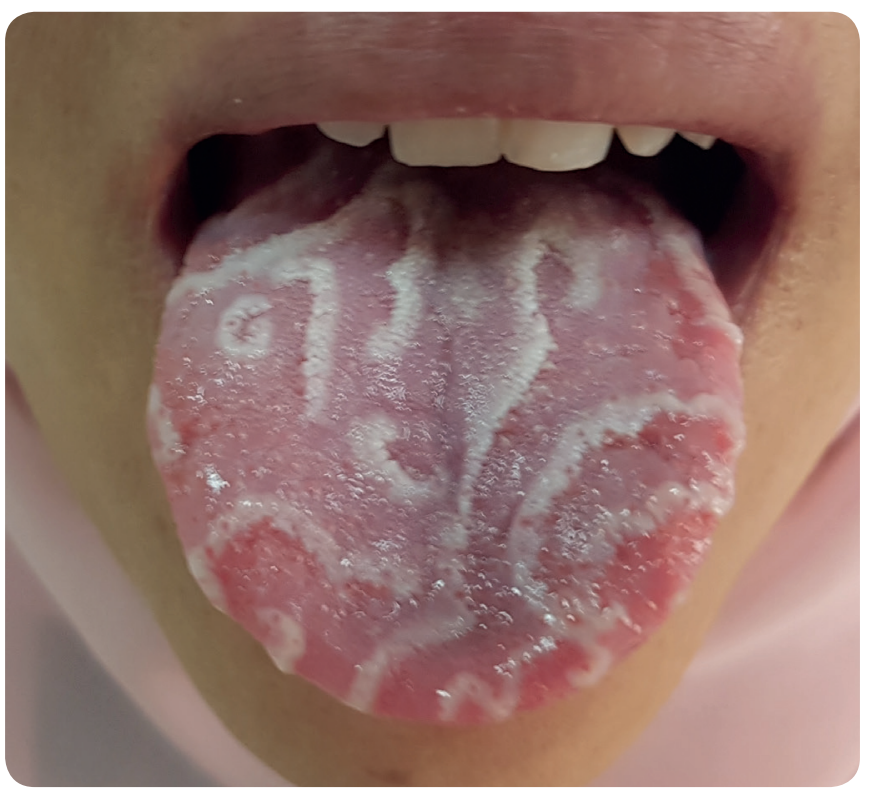

Fig. 1. White annular-serpiginous hyperkeratotic plaques in the dorsum of the tongue

Key words: geographic tongue
Geographical tongue (GT) is a chronic inflammatory condition that affects $4.8 \%$ of the population. It is thought to be a multifactorial disease including psychological factors, allergic status, psoriasis and nutritional deficiencies. ${ }^{1}$ Clinically, it is characterized by patches that cause annular, erythematous, slightly raised, map-like appearance. This appearance is caused by the atrophy of the filiform papilla. ${ }^{2}$

The mutation in the IL-36RN (encoding the interleukin-36 receptor antagonist) gene in the sporadic GT or familial GT was previously defined. Geographic tongue is thought to be a localized form of pustular psoriasis or clinical phenotype of IL-36Ra deficiency (DITRA). At the same time, IL-36Ra expression was found to be impaired in the tongue tissue of patients with GT without IL-36RN mutation. ${ }^{3}$

In asymptomatic cases, spontaneous recovery may be observed. Antihistamines, anxiolytic drugs, topical corticosteroids, anesthetics and the avoidance of spicy or acidic foods may be recommended in the treatment of symptomatic patients. ${ }^{2}$

It is known that the geographic tongue may be mucosal involvement of pustular psoriasis. ${ }^{1,2,3}$ Our patient had family history of psoriasis, we thought that geographic tongue might be related to the mucosal involvement of psoriasis in the differential diagnosis, although she refused biopsy.

Corresponding author: Murat Ozturk, Dept. of Dermatology, Health Sciences University Training and Research Hospital, Van, Turkey. Phone: +90 5424557707 E-mail: chayacholic@hotmail.com

Received: 2 November 2018 Accepted: 1 March 2019

Conflicts of Interest: None 
We present this beautiful image to emphasize the increased risk of psoriasis in patients with geographic tongue, although there is no skin involvement in our patient.

\section{References}

1. Picciani B, Santos VC, Teixeira-Souza T et al. Investigation of the clinical features of geographic tongue: unveiling its relationship with oral psoriasis. Int J Dermatol 2017;56:421-7.

2. de Campos WG, Esteves CV, Fernandes LG, Domaneschi C, Júnior CAL. Treatment of symptomatic benign migratory glossitis: a systematic review. Clin Oral Investig 2018;22:2487-93.

3. Sadlier M. Acrodermatitis continua of Hallopeau and geographic tongue are variants of pustular psoriasis. JAAD Case Rep 2018;4:277. 